\title{
Densification of (GNSS) Control Points for Cadastral and Mapping Purposes
}

\author{
Ehigiator M. O. ${ }^{1}$, Oladosu S. O. ${ }^{2} \&$ Ehigiator-Irughe, R. ${ }^{2} * *$ \\ ${ }^{1}$ Department of Physics, Benson Idahosa University, Benin City, Nigeria \\ ${ }^{2}$ Department of Geomatics, University of Benin, Benin City, Nigeria \\ Corresponding Author: *raphael.ehigiator@uniben.edu
}

\begin{abstract}
GNSS control densification is a continuous exercise in the field of Geomatics. This form the basis upon which other Geomatics and Engineering activities geared toward development are referenced. This paper employed the use of Hi-Target GPS to extend and establish controls at the confines of the study area in static mode while topographical survey was carried out using real-time kinematics method. Network adjustment, for the newly established control stations were carried out while the master station was held fixed. Data analysis and production of plans were done using softwares like Hi-Target V30, Carlson Civil Suite 2017 etc. The result of perimeter computation for the study area gave a total of 93.614 hectare
\end{abstract}

Keywords: Densification, Control Stations, GNSS Network, Cadastral, Mapping

\subsection{Introduction}

This paper discussed the concepts, instrumentation, office procedure, field work and software used in establishing control points located at a vast palm plantation farm at Igue-Iheya/Isioho in Ovia NorthEast Local Government Area of Edo State. Control extension is very important for surveying and mapping of any engineering project. GNSS is a versatile, accurate, quick, better, time-saving and economical way of establishing control points. The distance between the base station (UN_GPS_100) and the GPS_01 is $5399.578 \mathrm{~m}$.

\subsection{The concept of Static and Kinematics Modes in GNSS}

Gunter (2003), observed that various techniques have been developed in recent years that exploit the capability of GPS to provide precise coordinates after a very short observation time, or even while the receiver (including the antenna) is moving along a trajectory. Gunter (2003), stated that rapid methods require the resolution of ambiguities in order to exploit the high accuracy potential of GPS phase measurements. Otherwise the noise level of real valued solutions for the short observation times would be too high. One prerequisite the Global Positioning System (GPS) for the rapid solution of ambiguities is that the distant-dependent errors be small. Hence, the rapid methods only work well for short distances (up to several kilometres) between the participating stations. For longer ranges, it is necessary to model the distance dependent errors, e.g. in active reference networks.

Different possibilities exist for subdividing the rapid methods of GPS. The scheme used here is into three categories stated as follows;

i. Rapid static methods,

ii. Semi-kinematic (stop and go) methods, and

iii. Real kinematic methods.

It was noted by Seeber (2003), that the rationale behind this subdivision is whether the receiver is taking measurements while it is in motion, and the coordinates of the trajectory can be determined (kinematic 
mode), or whether the receiver is switched off during transportation, and coordinates can only be determined when the antenna is stationary (static mode). A third mode is in between these possibilities, in that the receiver has to maintain lock during the times of transportation, but coordinates are not usually derived for the trajectory (semi kinematic mode).

A further distinction between static and kinematic surveying can be seen with respect to accuracy issues (Kleusberg, 1990). In static GPS surveying, most random measurement errors are absorbed in the residuals after adjustment, while in kinematic surveying, most random measurement errors are absorbed in the coordinates. This is why the accuracy potential of static GPS cannot be reached completely with pure kinematic methods (Seeber, 2003). As the GPS signal finally arrives at the earth's surface, it may be reflected by local obstructions before it gets to the receiver's antenna. This is called multi-path error as the signal is reaching the antenna in single line path as well as delayed path.

Sources of errors in GNSS surveying include but not limited to: (i) the multipath effect is caused by reflection of satellite signals (radio waves) on objects. For GPS signals this effect mainly appears in the neighbourhood of large buildings or other elevations. The reflected signal takes more time to reach the receiver than the direct signal. The resulting error typically lies in the range of a few meters. (ii) Atmospheric Effects, the GPS signals have to travel through charged particles and water vapour in the atmosphere that delays its transmission. Since the atmosphere varies at different places and at different times, it is not possible to accurately compensate for the delays that occur. While radio signals travel with the velocity of light in the outer space, their propagation in the ionosphere and troposphere is slower. In the ionosphere (consisting of layers) in a height of $80-400 \mathrm{~km}$ a large number of electrons and positive charged ions are formed by the ionizing force of the sun. The layers refract the electromagnetic waves from the satellites, resulting in an elongated runtime of the signals. Since the Electromagnetic waves emit in form of a sphere, therefore, Inverse square law is employed and the waves are slowed down inversely proportional to the square of their frequency $\left(1 / \mathrm{f}^{2}\right)$ while passing the ionosphere. The reasons for the refraction in troposphere are different concentrations of water vapors, caused by different weather conditions. The error caused that way is smaller than the ionosphere error, but cannot be eliminated by calculation. It can only be approximated by a general calculation model. (iii) Receiver Error, since the receivers are also not perfect, they can introduce their own errors which usually occur from their clocks or internal noise. Despite the synchronization of the receiver clock with the satellite time during the position determination, the remaining inaccuracy of the time still leads to an error of about $2 \mathrm{~m}$ in the position determination. Rounding and calculation errors of the receiver sum up approximately to $1 \mathrm{~m}$ (CED, 2012).

\subsection{Reconnaissance and Monumentation}

This deals with gathering of information that is required to carry out a successful field operations. The choice of control point used as master station was made. This first order GNSS control established is located at University of Benin Ugbowo Campus close to Civil Engineering laboratory with the following inscription (UN_GPS_100). Field reconnaissance was then performed in the study area to ascertain how the ground conditions were as well as locating suitable points for the proposed new controls. Seven controls were established around the study area defining the boundaries which were later coordinated.

\subsection{Study Area}

The study area is at Igue-Iheya/Isiohor in Ovia North-East Local Government Area of Edo State, Nigeria. Its geographic location lie between Latitude: $6^{\circ} 25^{\prime} 33.24 " \mathrm{~N}$, Longitude: $5^{\circ} 34^{\prime} 16.03 " \mathrm{E}$ and Latitude $6^{\circ} 25^{\prime} 29.95^{\prime \prime} \mathrm{N}$, Longitude $5^{\circ} 35^{\prime} 33.25^{\prime \prime} \mathrm{E}$

\subsection{GNSS Network Design and Observation}

The GNSS observation started on the $3^{\text {rd }}$ of April, 2017 and ended on the $7^{\text {th }}$ of the same month. The network was designed in such a way that four controls were established at the corners and three other close to the middle of the project area. In each observation session a minimum of $45 \mathrm{mins}$ to 1 hour was used depending on the baseline length and satellite availability. Four Hi-Target V30/50 dual frequency 
geodetic L1/L2 rover receiver with geodetic antennas were used to simultaneously track the satellites. Number of GNSS Baselines in the network were 18 while the number of adjusted points were 8 .

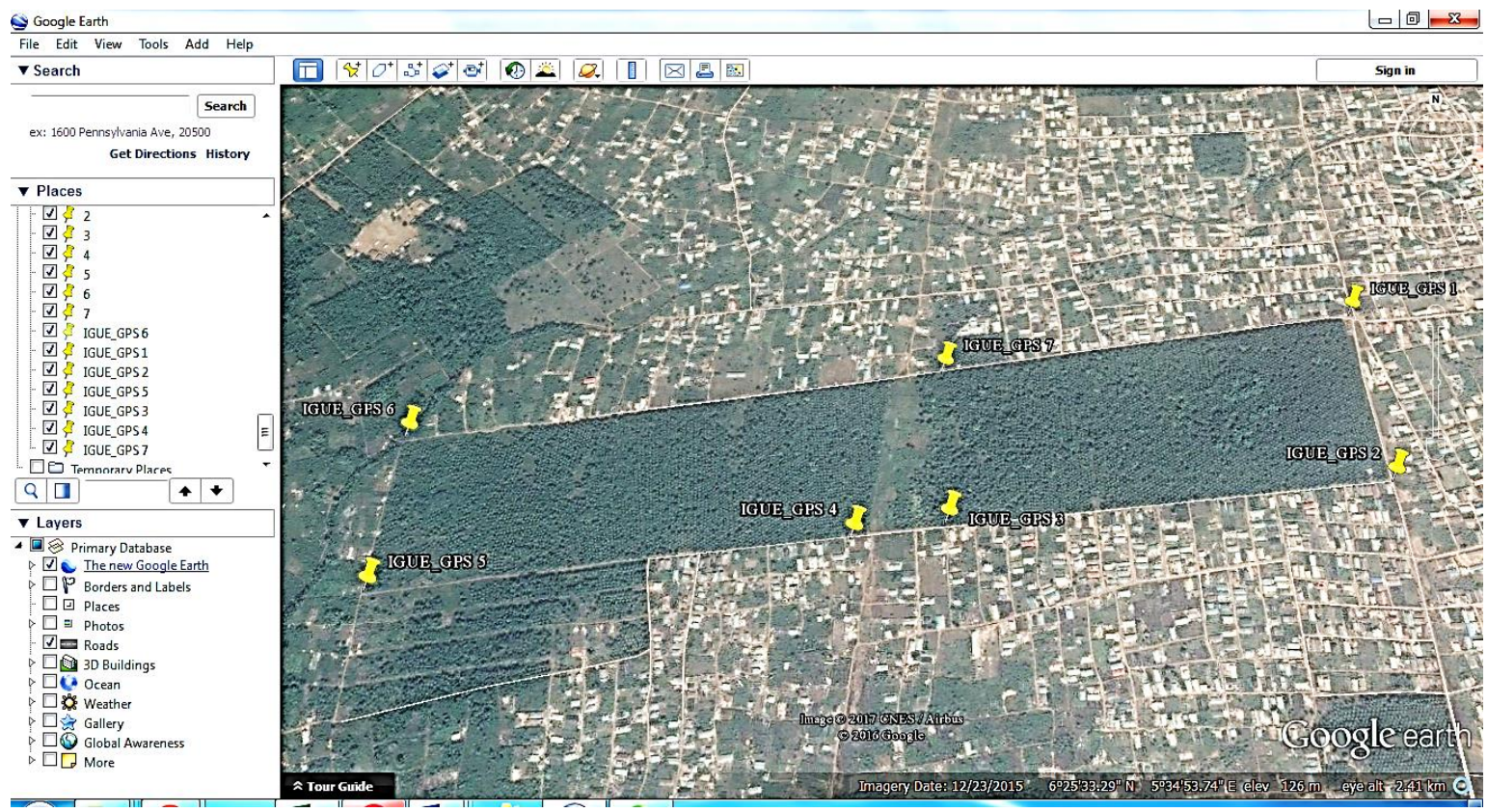

Figure 1: Screen shot of Google Earth Landsat Imagery of the study area boundaries are marked with yellow place marks

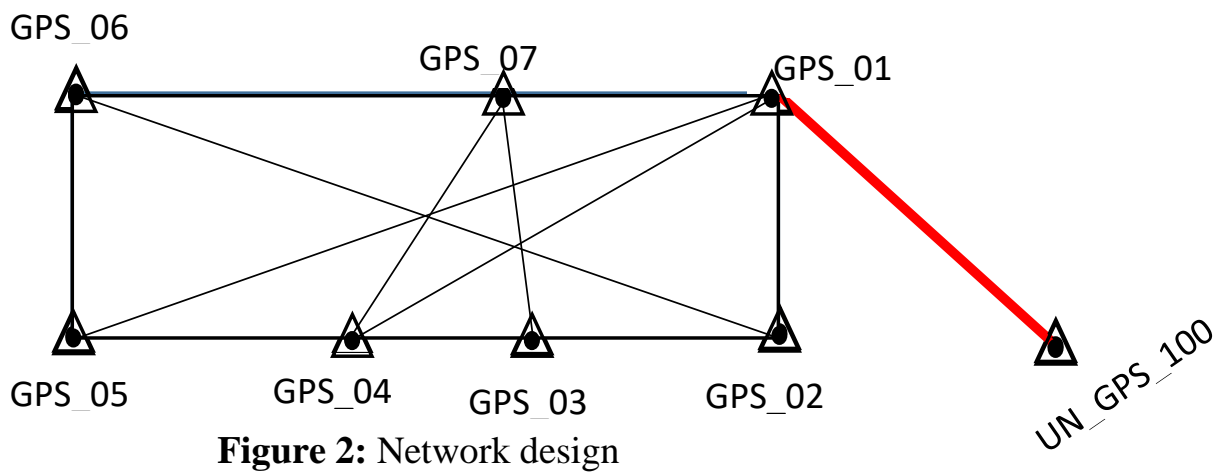

\subsection{GNSS Field Survey Operation Procedures}

Boundaries were coordinated using GNSS static mode. This involves setting up the master at the control point (UN_GPS_100) at UNIBEN while the other three rovers were set up at stations whose positions are required. Time of observation lasted between 45minutes to 1hour. For detailing and topographic survey, Real time kinematic mode was used. This involves setting up the master at one of the newly coordinated station at the site, using radio signal, corrections were transmitted to the rovers.

\subsection{Materials/Method}

\subsection{Instrumentation}

i. 1 x Hi Target V30 Dual Frequency GNSS (Global Navigation Satellite System) 'Base Station' receiver.

ii. 2 x Hi Target Dual Frequency V30 GNSS (Global Navigation Satellite System) 'Rover' receiver.

iii. 1 x Data Processing Computer and Accessories.

\subsection{Pseudorange Observation Equations}

The principle involves measurement of distance or range to at least four Satellites whose $X, Y$ and $Z$ positions are known, in order to define the user's $X_{\mathrm{p}}, Y_{\mathrm{p}}$ and $Z_{\mathrm{p}}$ position. In its simplest form, the satellite 
transmits signal on which the time of its departure $(t \mathrm{D})$ from the satellite is modulated. The receiver in turn notes the time of arrival $(t \mathrm{~A})$ of this time mark. The time taken from the transmitted signal to the receiver is given by, as $(t \mathrm{~A}-t \mathrm{D})=\Delta t$ (called the delay time). The measured range $R$ is obtained from equation 1(Geoffrey Blewitt, 2003).

$R_{1}=(t \mathrm{~A}-t \mathrm{D}) C=\Delta t C$

Where, $c=$ the velocity of light.

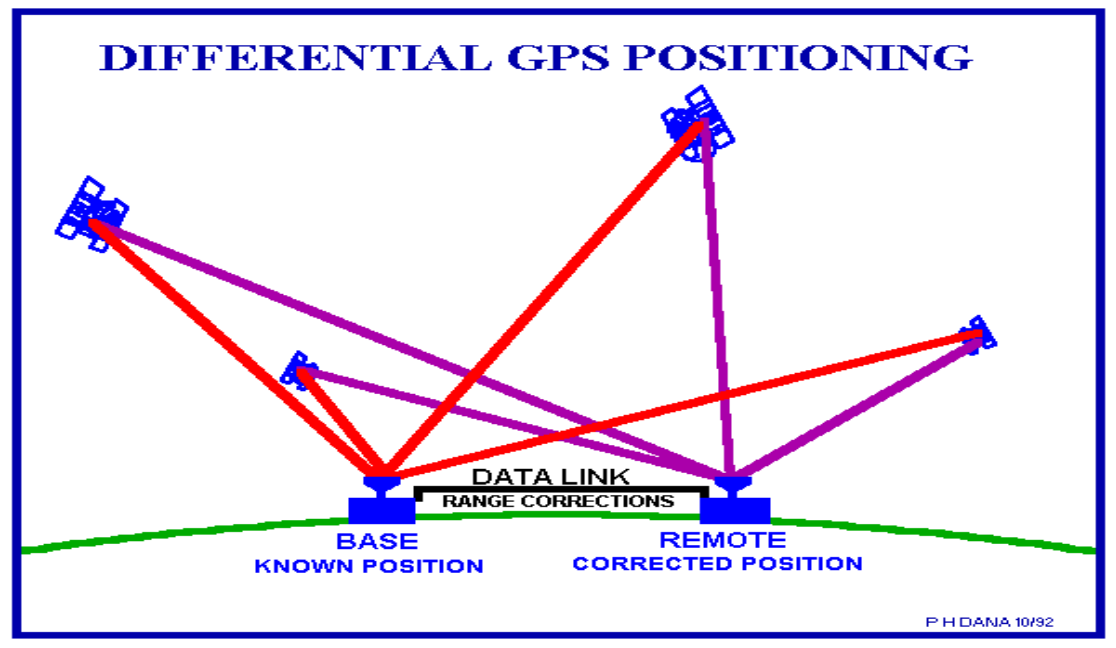

Figure 3: Pseudo - Range Measurement (Source: http//gps 2008.wordpress.com)

Figure 3 demonstrates what transpired between the satellite in space and the GNSS receiver on earth's surface for a single differencing mode techniques of data acquisition. By setting the clock time $T$ equal to the true receive time $t$ plus a clock bias $\tau$, model observation can be developed for both the receiver and satellite clocks as presented in equation 2 (Blewitt, 2003).

$$
\left.\begin{array}{l}
T=t+\tau \\
T^{S}=t^{S}+T^{S}
\end{array}\right\}
$$

The Receivers record data which are regular and are usually set at intervals say, every 2, 5, 10, 30 seconds, as defined by the receiver user and also a function of the task at hand. Receiver clock time $T$, readings are used to identify when the measurement was made (Ehigiator - Irughe and Ehigiator, 2012). Therefore, the value of $T$ at a measurement epoch is known exactly, and is written to the data file along with the observation, the unknown parameter is the true time of measurement. Therefore, the actual observation to satellites can be written thus:

$$
P^{S}=\left(T-T^{S}\right) C
$$

By substituting equating (2) into (3), we have

$$
\rho^{S}(t)=C\left((t+\tau)-\left(t^{S}+t^{S}\right)\right)
$$

By re - arranging, equation (4) we have

$$
\rho^{S}(t)=C\left(\left(t-t^{S}\right)+\left(\tau-\tau^{S}\right) C\right.
$$

Where $\mathrm{T}$ is time when the transmitted signal was received at Receiver ground station, $T^{S}$ is the satellite transmitted time, $\rho$ is the range, C, the speed of light is given as $299792458 \mathrm{~m} / \mathrm{s}$.

The Pseudorange from Satellite to Receiver is thus given as (Blewitt, 2003). 


$$
\rho^{S}\left(t, t^{S}\right)=\sqrt{\left(x^{S}\left(t^{S}\right)-x(t)\right)^{2}+\left(y^{S}\left(t^{S}\right)-y(t)\right)^{2}+\left(z^{S}\left(t^{S}\right)-z(t)\right)^{2}}
$$

The Navigation message allows us to compute the satellite position $\left(\mathrm{x}^{\mathrm{s}}, \mathrm{y}^{\mathrm{s}}, \mathrm{z}^{\mathrm{s}}\right)$ and the satellite clock bias $\tau^{\mathrm{S}}$. Therefore, we are left with 4 unknowns, the receiver position $(\mathrm{x}, \mathrm{y}, \mathrm{z})$ and the receiver clock bias $\tau$. It is important to determine the satellite position at transmission time, $t^{S}$. This is because the satellite range can change as much as 60 meters within 0.07 seconds from the time the signal was transmitted, to the time the signal was received. Starting with the receive time, $t$, the transmit time can be computed by an iterative algorithm known as "the light time equation," which can be written as follows (Blewitt, 2003).

$$
\left.\begin{array}{l}
t^{S}(0)=t=(T-\tau) \\
t^{S}(1)=t-\frac{\rho^{S}\left(t, t^{S}(0)\right)}{C} \\
t^{S}(2)=t-\frac{\rho^{S}\left(t, t^{S}(1)\right)}{C}
\end{array}\right\}
$$

The satellite position (and hence the range $\rho^{S}\left(t, t^{S}\right)$ is calculated at each step using the Keplerian-type elements from the Navigation Message. The algorithm is discontinued when there is convergent. Although more rapidly converging methods have been implemented, the above method is probably the easiest to understand. From equation (6) we can write a system of simplified observation equations from 4 satellites in view of the receiver. Using the above notation, we can write the pseudoranges equations for 4 satellite as (Ehigiator - Irughe and Ehigiator, 2012);

$$
\left.\begin{array}{l}
\rho^{1}=\left[\left(X_{1}-X_{p}\right)^{2}+\left(Y_{1}-Y_{p}\right)^{2}+\left(Z_{1}-Z_{p}\right)^{2}\right]^{1 / 2}+c \tau-c \tau^{1} \\
\rho^{2}=\left[\left(X_{2}-X_{p}\right)^{2}+\left(Y_{2}-Y_{p}\right)^{2}+\left(Z_{2}-Z_{p}\right)^{2}\right]^{1 / 2}+c \tau-c \tau^{2} \\
\rho^{3}=\left[\left(X_{3}-X_{p}\right)^{2}+\left(Y_{3}-Y_{p}\right)^{2}+\left(Z_{3}-Z_{p}\right)^{2}\right]^{1 / 2}+c \tau-c \tau^{3} \\
\rho^{4}=\left[\left(X_{4}-X_{p}\right)^{2}+\left(Y_{4}-Y_{p}\right)^{2}+\left(Z_{4}-Z_{p}\right)^{2}\right]^{1 / 2}+c \tau-c \tau^{4}
\end{array}\right\}
$$

Where $\mathrm{X}_{\mathrm{n}}, Y_{n}, Z_{n}=$ the coordinates of satellites $1,2,3$ and 4 ( $n=1$ to 4$)$

$X_{\mathrm{p}}, Y_{\mathrm{p}}, Z_{\mathrm{p}}=$ the coordinates required for point $\rho$

\subsection{Phase Differencing Modes}

There are three types of phase differencing modes in GNSS observation, these are; (1) Single, (2) Double and (3) Triple respectively. For this project the mode employed is double differencing mode which shall be discussed as follow.

\subsection{Double Differencing Mode}

The double-difference mode is executed between a pair of receivers and pair of satellites as shown in Figure (3). It involves taking the difference of two single differences obtained from two satellites $\mathrm{j}$ and $\mathrm{k}$. The procedure eliminates the receiver clock bias as follows;

$$
\left.\begin{array}{l}
\phi_{A B}^{j}(t)=\frac{1}{\lambda} \rho_{A B}^{j}(t)+N_{A B}^{j}-f^{j} \delta_{A B}^{j}(t) \\
\phi_{A B}^{k}(t)=\frac{1}{\lambda} \rho_{A B}^{k}(t)+N_{A B}^{k}-f^{k} \delta_{A B}^{k}(t)
\end{array}\right\}
$$




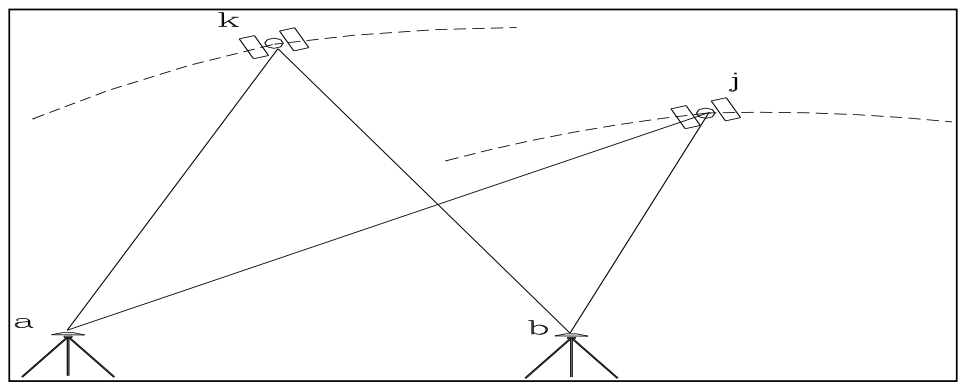

Figure 4: The Double-Difference Technique.

Taking the differences between the two equations in (9) the receiver clock errors, $f^{j} \delta_{A B}^{j}(t)$ and $f^{k} \delta_{A B}^{k}(t)$ are eliminated thus;

$\phi_{a, b}^{j}(t)-\phi_{a, b}^{k}(t)=\frac{1}{\lambda}\left[\rho_{a, b}^{j}(t)-\rho_{a, b}^{k}(t)\right]+\left[N_{a, b}^{j}-N_{a, b}^{k}\right]$

Using the short hand notation as in the single-difference

$\phi_{a, b}^{j, k}(t)=\frac{1}{\lambda} \rho_{a, b}^{j, k}(t)+N_{a, b}^{j, k}$

The result of this mode is the omission of the receiver clock offsets. The double-difference model for long baselines when there is a significant difference in the atmospheric effect between the two baselines ends can be expressed as:

$\phi_{a, b}^{j, k}(t)=\frac{1}{\lambda} \rho_{a, b}^{j, k}(t)+N_{a, b}^{j, k}-\frac{1}{\lambda} \Delta_{a, b}^{j, k} \operatorname{Ion}(t)+\frac{1}{\lambda} \Delta_{a, b}^{j, k} \operatorname{Trop}(t)$

\subsection{Linearised Model}

For completeness, we summarize the linearisation procedure and the development of the least squares method specifically for the GPS point positioning problem. First, we assume we can write the actual observation to be the sum of a modelled observation, plus an error term;

$$
\left.\begin{array}{l}
P_{\text {observed }}=P_{\text {model }}+\text { noise } \\
=P(x, y, z, \tau)+v
\end{array}\right\}
$$

The provisional parameter values is given as $\left(x_{0}, y_{0}, z_{0}, \tau_{0}\right)$, using Taylor's theorem the computed model can be expanded thus by ignore second and higher order terms.

$$
P(x, y, z, \tau)=\left\{\begin{array}{l}
P\left(x_{0}, y_{0}, z_{0}, \tau_{0}\right)+\left(x-x_{0}\right) \partial P / \partial x+\left(y-y_{0}\right) \partial P / \partial y+\left(z-z_{0}\right) \partial P / \partial z+\left(\tau-\tau_{0}\right) \partial P / \partial \tau \\
=P_{\text {computed }}+\partial P / \partial x \Delta x+\partial P / \partial y \Delta y+\partial P / \partial z \Delta z+\partial P / \partial \tau \Delta \tau
\end{array}\right\}
$$

The residual observation is the difference between the actual observation and the computed using the provisional parameter values i.e.

$$
\Delta P=P_{\text {observed }}-P_{\text {computed }}=\frac{\partial p}{\partial x} \Delta x+\frac{\partial p}{\partial y} \Delta y+\frac{\partial p}{\partial z} \Delta z+\frac{\partial p}{\partial \tau} \Delta \tau+v
$$

The matrix form is given as: 
$\Delta P=\left[\frac{\partial P}{\partial x} \frac{\partial P}{\partial y} \frac{\partial P}{\partial z} \frac{\partial P}{\partial \tau}\right]\left[\begin{array}{l}\Delta x \\ \Delta y \\ \Delta z \\ \Delta \tau\end{array}\right]+v$

The above equation is for one satellite, for $\mathrm{n}$ satellite, we can develop similar equation which is often written as:

$$
b=A x+v
$$

The estimated residual is given as:

$$
v=b-A x
$$

The "least squares" solution can be found by varying the value of ' $x$ ' until the following functional is minimized thus:

$$
J(X)=\sum_{j=1}^{m} v_{i}^{2}=v^{T} v=(b-A x)^{T}(b-A x)
$$

The normal equation to the solution is given as:

$$
\hat{x}=\left(A^{T} A\right)^{-1} A^{T} b
$$

The design matrix A which is usually the partial derivatives of each observation with respect to each parameter derived from the provisional values assuming $n=4$ and data $m$, which can be written as:

$$
A=\left\{\begin{array}{l}
\frac{x_{0}-x^{1}}{\rho} \frac{y_{0}-y^{1}}{\rho} \frac{z_{0}-z^{1}}{\rho} c \\
\frac{x_{0}-x^{2}}{\rho} \frac{y_{0}-y^{2}}{\rho} \frac{z_{0}-z^{2}}{\rho} c \\
\frac{x_{0}-x^{m}}{\rho} \frac{y_{0}-y^{m}}{\rho} \frac{z_{0}-z^{m}}{\rho} c
\end{array}\right\}
$$

\subsection{Datum Transformation}

The term Datum is used to describe the reference frame for geodetic computation which define the parameters regarding the relationship between the ellipsoid and the real earth (Geoid). The position of a point on the earth surface can be given either in terms of $(\varphi, \kappa, h)$ or $(X, Y, Z)$ coordinates systems. Whist every systems used have an origin and have a relationship for transformation to other systems. The transformation from $(\varphi, \kappa, h)$ system to $(X, Y, Z)$ system can be achieved using the following relationship.

$$
\left.\begin{array}{l}
X=[N+h] \cos \phi \cos \lambda \\
Y=[N+h] \cos \phi \sin \lambda \\
Z=\left[N\left(1-e^{2}\right)+h\right] \sin \phi
\end{array}\right\}
$$

Where $\boldsymbol{N}$ is radius vector of the prime vertical, $\boldsymbol{h}$ is the point above ellipsoid, $\boldsymbol{e}$ is the eccentricity. $\boldsymbol{N}$ and $\boldsymbol{e}$ are given by:

$$
\left.\begin{array}{l}
e^{2}=2 f-f^{2} \\
N=\frac{a}{\left(1-e^{2} \sin ^{2} \phi\right)^{1 / 2}}
\end{array}\right\}
$$

Where, $\boldsymbol{a}$, is the major axis of the earth and $\boldsymbol{f}$, is the flattening of the reference ellipsoid. For WGS84, $\boldsymbol{a}$ $=6,378,137 \mathrm{~m}, \boldsymbol{f}=1 / 298.257223563=0.003352810665$. 
The inverse formula for obtaining $\boldsymbol{\varphi}, \boldsymbol{\kappa}, \boldsymbol{h}$ from $\boldsymbol{X}, \boldsymbol{Y}, \boldsymbol{Z}$ is

$\left.\begin{array}{l}\tan \lambda=Y / X \\ \tan \phi=\left(Z+e^{2} N \sin \phi /\left(X^{2}+Y^{2}\right)^{1 / 2}\right. \\ h=(N+H)=(X \sec \lambda \sec \phi)-N\end{array}\right\}$

Where, $\boldsymbol{N}$ is the geoidal undulation, $\boldsymbol{H}$ is the orthometric height

Using equations (1), the coordinate of the reference station was transformed to its equivalent geodetic coordinates in (WGS84) and the result is as presented in Table 1. Table 1a shows, the coordinate of the master control station in terms of longitude, latitude and height in the world geodetic coordinate system. Table $1 \mathrm{~b}$ shows, the coordinate of the master control station in terms of Cartesian coordinate world geodetic coordinate system.

Table1a: Reference Points in WGS84 (BLH) coordinate

\begin{tabular}{|c|c|c|c|c|c|c|}
\hline Stn/ Name & Lat $(\mathbf{m})$ & $\begin{array}{c}\text { Std.Dev } \\
(\mathbf{m m})\end{array}$ & Lon $(\mathbf{m})$ & $\begin{array}{c}\text { Std.Dev } \\
(\mathbf{m m})\end{array}$ & H (m) & $\begin{array}{c}\text { Std.Dev } \\
(\mathbf{m m})\end{array}$ \\
\hline UN_GPS_100 & $006: 24: 13.88500 \mathrm{~N}$ & 0.0 & $005: 36: 57.82950 \mathrm{E}$ & 0.0 & 129.2223 & 0.0 \\
\hline
\end{tabular}

Table 1b: Reference point in WGS 84 (NEU) coordinate

\begin{tabular}{|c|c|c|c|c|c|c|}
\hline Stn/ Name & $\mathbf{X}(\mathbf{m})$ & $\mathbf{Y}(\mathbf{m})$ & $\mathbf{U}(\mathbf{m})$ & $\begin{array}{c}\text { Std.Dev_N } \\
(\mathbf{m m})\end{array}$ & $\begin{array}{c}\text { Std.Dev_E } \\
(\mathbf{m m})\end{array}$ & $\begin{array}{c}\text { Std.Dev_U } \\
(\mathbf{m m})\end{array}$ \\
\hline UN_GPS100 & 6308306.5178 & 620320.5452 & 706672.3149 & 0.0 & 0.0 & 0.0 \\
\hline
\end{tabular}

Table 2: Adjusted Points in WGS84 (XYZ)

\begin{tabular}{|c|c|c|c|c|c|c|c|}
\hline Station From & Station To & $\mathbf{X}(\mathbf{m})$ & $\mathbf{Y}(\mathbf{m})$ & $\mathbf{Z}(\mathbf{m})$ & $\begin{array}{c}\text { Std.Dev } \\
\mathbf{X}(\mathbf{m m})\end{array}$ & $\begin{array}{c}\text { Std.Dev_ } \\
\mathbf{Y}(\mathbf{m m})\end{array}$ & $\begin{array}{c}\text { Std.Dev } \\
\mathbf{Z}(\mathbf{m m})\end{array}$ \\
\hline IGUE_GPS_01 & UB_GPS100 & 6308270.1677 & 617684.1797 & 709442.2558 & 221.4 & 165.5 & 104.0 \\
\hline IGUE_GPS_02 & IGUE_GPS_03 & 6308311.1310 & 617705.4102 & 709007.9638 & 166.9 & 112.3 & 89.8 \\
\hline IGUE_GPS_03 & IGUE_GPS_04 & 6308573.4899 & 615336.6332 & 708732.1312 & 117.0 & 75.1 & 61.3 \\
\hline IGUE_GPS_04 & IGUE_GPS_05 & 6308534.4371 & 615349.9549 & 709096.0886 & 189.9 & 86.1 & 75.9 \\
\hline IGUE_GPS_05 & IGUE_GPS_06 & 6308397.1361 & 616529.1721 & 709273.9753 & 142.5 & 59.2 & 65.9 \\
\hline IGUE_GPS_06 & IGUE_GPS_07 & 6308445.3406 & 616467.4822 & 708871.8646 & 183.9 & 70.5 & 97.7 \\
\hline IGUE_GPS_07 & IGUE_GPS_01 & 6308310.0199 & 617710.3923 & 709013.1154 & 206.5 & 77.3 & 107.8 \\
\hline IGUE_GPS_01 & UB_GPS100 & 6308306.5178 & 620320.5452 & 706672.3149 & 0.0 & 0.0 & 0.0 \\
\hline
\end{tabular}

The adjusted points in Table 2 are the coordinates of the control point established with their corresponding standard deviations produced by the software after performing network adjustment.

\subsection{GPS Data Downloading and Processing}

The data was downloaded from the master and rover GPS into the computer and Hi-Target software was used to process the data which was then used in Auto CAD and ArcGIS to produce the plan and three-dimensional map of the project area.

\subsection{Adjustments of Observations}

The qualities to be obtained after field measurements and adjustment in a GNSS network involving both adjusted and unadjusted baseline vector components, their covariance and the final coordinates. We perform baseline adjustment using UB_GPS_100 as our master control point which was held fixed. 
The Geodetic coordinates in (WGS 84) for GPS_01 for example can be derived by taking into account the baseline that connect it to the master control as presented in Table 3. To determine the Geodetic coordinates of other points, the baselines of observations must be considered in succession in the network. The Geodetic coordinates for (IGUE) GPS_01, the baseline is from UB_GPS_100. For (IGUE) GPS_02, the baseline is from (IGUE) GPS_01 and so on .This relationship can be presented for the first baseline as we have in equation (24);

$$
\begin{aligned}
& \left.\left[U B_{-} G P S_{-} 100\right] X=X_{\text {Igue }_{-} \text {gps_o1 }}+\Delta X_{\text {Corrected }}+V x\right] \\
& {\left[U B \_G P S_{-} 100\right] Y=Y_{\text {Igue }_{\text {gps }} 01}+\Delta Y_{\text {Corrected }}+V y}
\end{aligned}
$$

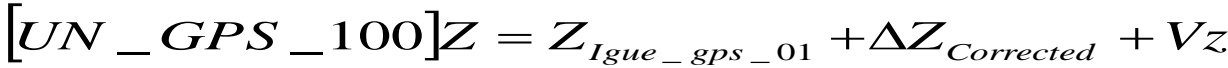

Using equation (24), other positions were determined with respect to their corresponding baselines. Our results are presented for other points in table 3. Equations 16, 17, 18, 19 and 20 played vital roles in the adjustment procedure.

\begin{tabular}{|c|c|c|c|c|c|c|c|c|c|c|c|c|c|}
\hline \multicolumn{2}{|c|}{ Baseline } & \multicolumn{3}{|c|}{ Uncorrected Baseline } & \multicolumn{3}{|c|}{ Baseline Residual } & \multicolumn{3}{|c|}{ Corrected Baseline } & \multirow[t]{2}{*}{ Northing } & \multirow[t]{2}{*}{ Easting } & \multirow[t]{2}{*}{ Ellip. Hgt } \\
\hline From & To & $\Delta \mathbf{X}$ & $\Delta \mathbf{Y}$ & $\Delta \mathbf{Z}$ & $\begin{array}{l}V x \\
(\mathrm{~m})\end{array}$ & $\begin{array}{l}\mathrm{Vy} \\
(\mathrm{m})\end{array}$ & $\begin{array}{l}\mathrm{Vz} \\
(\mathrm{m})\end{array}$ & $\Delta \mathbf{X}$ & $\Delta \mathbf{Y}$ & $\Delta \mathbf{Z}$ & & & \\
\hline \multicolumn{2}{|c|}{$\begin{array}{l}\text { UB_GPS100 } \\
\text { (master control) }\end{array}$} & 0 & 0 & 0 & 0 & 0 & 0 & 0 & 0 & 0 & 6308306.5178 & 620320.5452 & 706672.3149 \\
\hline IGUE_GPS_01 & UB_GPS100 & 36.35 & 2636.36 & -2769.94 & 0.0810 & -0.0721 & 0.1233 & 221.4 & 165.5 & 104.0 & 6308270.1677 & 617684.1797 & 709442.2558 \\
\hline IGUE_GPS_02 & IGUE_GPS_03 & -40.96 & -21.23 & 434.29 & 0.0771 & 0.0377 & 0.0082 & 166.9 & 112.3 & 89.8 & 6308311.1310 & 617705.4102 & 709007.9638 \\
\hline IGUE_GPS_03 & IGUE_GPS_04 & -262.35 & 2368.77 & 275.83 & 0.0820 & 0.0319 & -0.0281 & 117.0 & 75.1 & 61.3 & 6308573.4899 & 615336.6332 & 708732.1312 \\
\hline IGUE_GPS_04 & IGUE_GPS_05 & 39.05 & -13.32 & -363.95 & -0.0011 & -0.0394 & -0.0063 & 189.9 & 86.1 & 75.9 & 6308534.4371 & 615349.9549 & 709096.0886 \\
\hline IGUE_GPS_05 & IGUE_GPS_06 & 137.30 & -1179.21 & -177.88 & 0.0973 & -0.0222 & 0.0378 & 142.5 & 59.2 & 65.9 & 6308397.1361 & 616529.1721 & 709273.9753 \\
\hline IGUE_GPS_06 & IGUE_GPS_07 & -48.20 & 61.68 & 402.11 & 0.2423 & 0.0113 & -0.0418 & 183.9 & 70.5 & 97.7 & 6308445.3406 & 616467.4822 & 708871.8646 \\
\hline IGUE_GPS_07 & UB_GPS100 & 135.32 & -1242.91 & -141.25 & 0.0302 & -0.0325 & 0.0010 & 206.5 & 77.3 & 107.8 & 6308310.0199 & 617710.3923 & 709013.1154 \\
\hline
\end{tabular}

Table 3: Baseline Residuals

In Table 3, the station points, the master station in red held fixed, the vectors of corrected and uncorrected baselines also the coordinates of points including the eastings, northings and heights of each points.

Table 4: Adjusted Points in Target System (NEU)

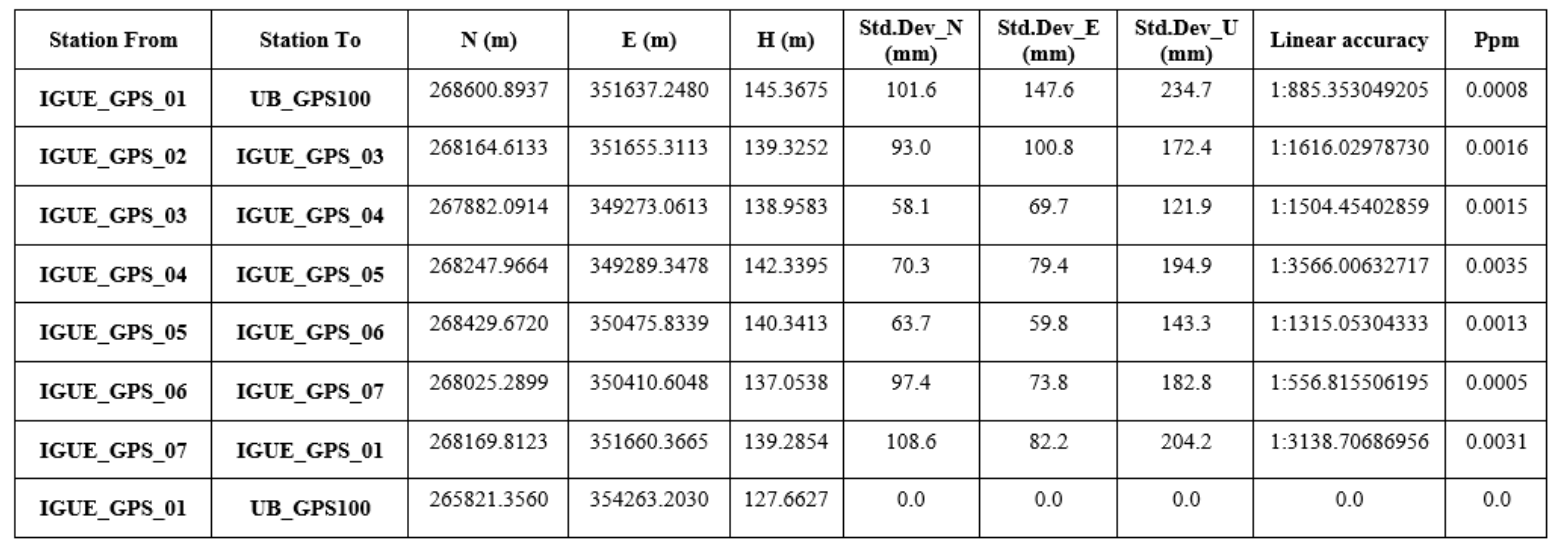

Table 4 shows the stations, adjusted points and their standard deviations in the target system (national system) standard deviation of zeros indicate a control point that was fixed and is assumed to be error free. The accuracy in part per million was presented and the distances of each base line as well. 
The formula to perform the Molodensky Abridge Model for transforming WGS84 to the equivalent Minna datum Geographical coordinates read thus:

$$
\begin{aligned}
& \Delta \varphi^{\prime \prime}=\left[-t_{x} \operatorname{Sin} \varphi \operatorname{Cos} \lambda-t_{y} \operatorname{Sin} \varphi \lambda+t_{z} \operatorname{Cos} \varphi+(a \Delta f+f \Delta a) \operatorname{Sin} 2 \varphi /\left(M \operatorname{Sin} 1^{\prime \prime}\right)\right] \\
& \Delta \lambda^{\prime \prime}=\left[-t_{x} \operatorname{Sin} \lambda+t_{y} \operatorname{Cos} \lambda\right] /\left(V \operatorname{Cos} \varphi \operatorname{Sin} 1^{\prime \prime}\right] \\
& \Delta \varphi^{\prime \prime}=\left[-t_{x} \operatorname{Sin} \varphi \operatorname{Cos} \lambda-t_{y} \operatorname{Sin} \varphi \lambda+t_{z} \operatorname{Cos} \varphi+(a \Delta f+f \Delta a) \operatorname{Sin}^{2} \varphi /\left(M \operatorname{Sin} 1^{\prime \prime}\right)\right] \\
& V_{(\varphi)}=\frac{a_{L}}{\left(1-e^{2} \operatorname{Sin}^{2} \varphi\right)^{\frac{1}{2}}}, M_{(\varphi)}=\frac{a_{L}\left(1-e^{2}\right)}{\left(1-e^{2} \operatorname{Sin}^{2} \varphi\right)^{\frac{3}{2}}}
\end{aligned}
$$

Where:

$t_{x}, t_{y}, t_{z}$ are the translations between both datums (in geocentric coordinates);

$\varphi, \lambda, \mathrm{h}$ : geodetic co-ordinates of the local geodetic system ellipsoid;

$\Delta \varphi, \Delta \lambda, \Delta \mathrm{h}$ : corrections to transform local datum co-ordinates to WGS $84 \varphi, \lambda, \mathrm{h}$;

$\Delta \mathrm{X}, \Delta \mathrm{Y}, \Delta \mathrm{Z}$ : corrections to transform local datum co-ordinates to WGS84 X, Y, Z;

$\Delta \mathrm{a}, \Delta \mathrm{f}$ : (WGS84 minus local) semi-major axis and flattening respectively;

$a$ : semi-major axis of the local geodetic system ellipsoid;

$f$ : flattening of the local geodetic system ellipsoid;

$\mathbf{M}_{(\varphi)}$ : radius of curvature in the meridian;

$\mathrm{V}_{(\varphi)}$ : Prime vertical radius of curvature;

The datum shift parameters derived by Shell Petroleum Development Company (SPDC) are presented thus: Datum Shift Parameters from WGS84 to Minna Datum Geographical coordinates are:

$$
\begin{array}{clr}
t_{x}=\text { plus } 111.916 & t_{y}=\text { plus } 87.852 & t_{z}=\text { minus } 114.499 \\
a_{L}=6378249.145 & f_{L}=1 / 293.465 & \Delta f=\text { minus } 0.54750714
\end{array}
$$

$\Delta a=112.145$

The accuracy standard for each baseline can be derive from linear accuracy relationship given as:

$$
1:\left\{\left[V x^{2}+V y^{2}+V z^{2}\right]^{1 / 2} / l_{a c}\right\}
$$

$\mathrm{Vx}, \mathrm{Vy}$ and $\mathrm{Vz}$ are as presented in table (4) and $l_{a c}$ is the baseline length.

Dividing equation (27) by 1,000,000 gives the accuracy in part per million (ppm).

\subsection{Analysis of Results and Plan Production}

Adjustment of data made it possible for further use in a GIS software environment. AutoCAD enables the plan of the project area to be plotted and is as presented in the following Figures 5a and 5b. Figure 5 a shows the contour which depict the difference in height as one traverse from one point to the other within the project site. This is usually useful for engineers in project design. Figure $5 \mathrm{~b}$ depict the modelling of surface water flow on the project site assuming water is allowed to freely flow on the project site. This will be of value should there be a need to control or monitor erosion on the site. 


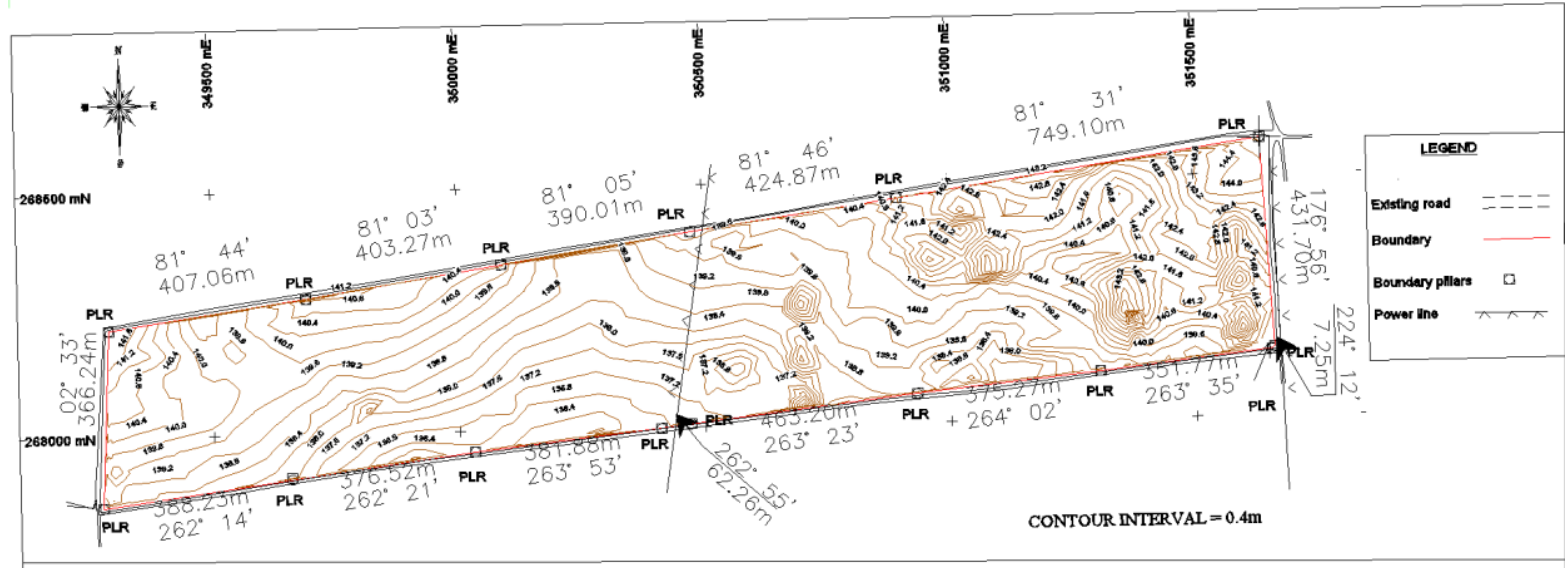

Figure 5a: Contour Plot of Study Area

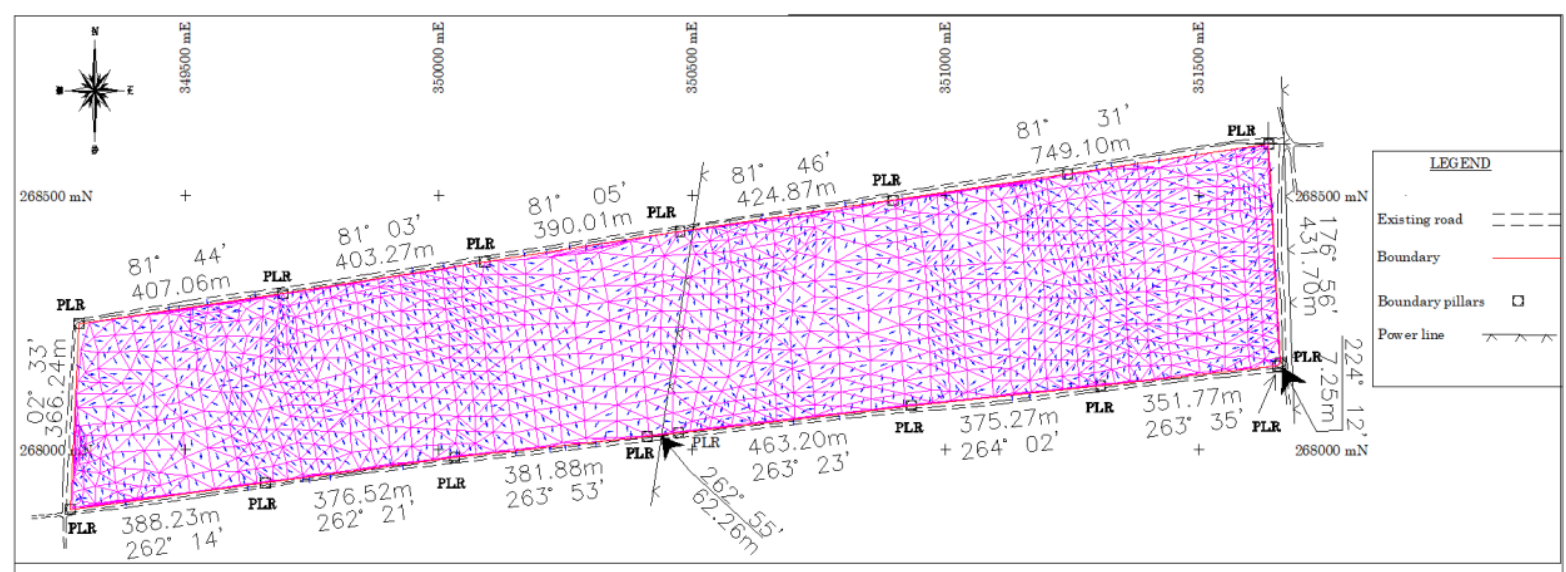

Figure 5b: Model of direction of flow of water across the entire land mass

Due to the fact that no satellites under horizon are available, GPS receivers can only receive signals from satellites above ground. This results in a poor geometry for fixing the height component in GPS measurements. In contrast, the horizontal components are fixed by satellites from different azimuths of the sky. It is therefore the VDOP value is higher than the HDOP value and the accuracy of vertical component is often less precise than horizontal one by 2 to 3 times or even more depending on the satellite geometry (Choi et al, 2007). The height $(\mathrm{H})$ used in producing the plan in figure $5 \mathrm{c}$ was presented in table 3 alongside the coordinate of points in the horizontal $(\mathrm{X}, \mathrm{Y})$ plane. At confidence level of $10.00 \sigma$, significance level for tau test: $1.00 \%$ and ratio of standard error of unit weight: 61.7841 . The accuracy of the heights are not as good as that of the horizontal due to Satellite Constellation: Tropospheric Delay, Phase Centre Variation (PCV) and Offset: Multipath, Geoid-ellipsoid Separation Accuracy etc. as can be observed from table 4 considering the standard deviation in E,N and H. EGM 2008 was used to obtain the orthometric heights within the project area.

The heights used as anchor points in determining relative heights of other points within the network used to model water flow direction in figure 3 was presented in table 4 and the accuracy of each station was computed using the baseline residual values substituted in equation 27 provided earlier.

\subsection{Conclusion and Recommendation}

GNSS controls were successfully established at Igue-Iheya/Isiohor palm plantation farm, these controls can serve as bases for future surveying and mapping exercise around the area. (GNSS) method of densifying control is a versatile, accurate, quick, better, time-saving and economical way of establishing control points. It is therefore recommended that surveyors and mapping agencies should key into the enormous advantages of DGPS in establishing control stations through this high precision technique for mapping within an area where controls are not readily available.

Although, one master (base) control point have been used in this work, for best practices it is good to use two or three control points. Time of occupation should be considered based on base line length, this 
will minimize error propagation within the network and further increase the reliability and accuracy level.

\section{References}

California Surveying and Drafting Supply (2015). "The importance of GNSS site calibration" http://w.w.w.csdsinc.com/the-importance -of-a-gnss-site-calibration/ assessed 31/05/17.

Choi D. C. T., Wong J. Y. K. and Chan B. S. B. (2007) "Investigation on GPS Heighting Accuracy with the use of Hong Kong Satellite Positioning Reference Station Network (SatRef) Strategic Integration of Surveying Services" FIG Working Week 2007 Hong Kong SAR, China, 13-17 May 200.7

Ehigiator - Irughe R., and Ehigiator O.M. (2011) “3D Modelling of Quarry Site using GPS Observations" Journal of Emerging Trends in Engineering and Applied Sciences (JETEAS) 2 (3): pp. 419-428 Scholarlink Research Institute Journals UK

Ehiorobo, J.O. and Ehigiator - Irughe, R., (2012). Evaluation of Absolute Displacement of Geodetic Control for Dam Deformation Monitoring Using CSRS-PPP Model. Journal of Earth Science and Engineering (USA) vol. 2, pp.277 - 286.

Blewitt G. (2003). Basics of the GPS Technique: Department of Geomatics, University of Newcastle Newcastle upon Tyne, NE1 7RU, United Kingdom Appears in the textbook "Geodetic Applications of GPS," published by the Swedish Land Survey.

Seeber G. (2003) Satellite Geodesy 2nd completely revised and extended edition Walter de Gruyter ·Berlin · New York 2003. Pp.289-290.

Ghosh K. J., Ojasa and Goyal, (2009). Establishment of Local Control Points for Mapping using GPS https://www.geospatialworld.net/article/establishment-of-local-control-points-for-mapping-using-gps/

Dana P. H. (2015). Global Positioning System Overview online material. Copyright () 1999-2015

Oki S., (2011) Control Point Surveying and Topographic Mapping - Civil Engineering - Vol. I Encyclopedia of Life Support Systems (EOLSS) Land Bureau, National Land Agency, Japan http://www.eolss.net/sample-chapters/c05/e6-37-02-01.pdf 